\title{
Emociones en la montaña rusa: El folklore de jóvenes y adolescentes entre las viejas y nuevas formas de expresión
}

\author{
Roller coaster emotions: \\ The folklore of young people and teenagers between \\ old and new forms of expression
}

\author{
Luisa AbAD GonZÁLEZ \\ (Universidad de Castilla La Mancha) \\ Luisa.Abad@uclm.es \\ ORCID ID: 0000-0003-3445-3158
}

\begin{abstract}
ResumEn: El texto explora el folklore estudiantil ABSTRACT: The text explores student folklore en su interconexión con el mundo digital y in its interconnection with the digital world con el mantenimiento de anteriores formas de and with the maintenance of previous forms expresión del folklore. Mediante un estudio of folklore expression. Through a qualitative cualitativo que ha sido desarrollado a través study that has been developed through a de una etnografía colaborativa complementada collaborative ethnography complemented with con entrevistas semidirigidas a grupos de semi-directed interviews with high school estudiantes de bachillerato y Universidad, se and university student groups, the role of analiza el papel de los juegos juveniles, como youth games, such as drinking and smoking los de beber y fumar, los llamados retos virales, games, the so-called viral challenges, whose cuyo relato va dirigido a jóvenes adolescentes, story is aimed at young adolescents, to end up para terminar abordando la comunicación con addressing communication with memes as a memes como práctica social dentro del contexto social practice within the context of Whatsapp de los grupos de Whatsapp. groups.
\end{abstract}

Palabras-ClaVe: Adolescentes y jóvenes, KeYwords: Teenagers and young people, digital folklore digital, etnografía colaborativa, folklore, collaborative ethnography, emotions, emociones, humor. humor.

Los jóvenes de ahora aman el lujo, tienen pésimos modales y desdeñan la autoridad. Muestran poco respeto por sus superiores y ya no se levantan cuando alguien entra en casa. Prefieren insulsas conversaciones al ejercicio y están dispuestos a contradecir a sus padres y a tiranizar a sus maestros. (Sócrates. Siglo IV a. C.)

\section{INTRODUCCIÓN}

Quisiéramos comenzar este artículo aprovechando esta - tan conocida como manida - cita de Sócrates poniendo en evidencia la adultocéntrica y reiterativa crítica hacia el comportamiento juvenil a lo largo de la historia, para ir estableciendo, en la 
medida de lo que nos sea posible, el posicionamiento argumentativo en el que nos hemos basado a la hora de realizar este estudio.

Recientemente, en una investigación realizada en 146 países por la OMS y dirigida por la Dra. Regina Guthold (Guthold, Stevens, Realey y Bull, 2020) se informaba que los adolescentes no realizan suficiente actividad física, lo que supone un serio riesgo para su salud presente y futura, poniéndose de manifiesto, además, la existencia de una importante brecha de género en detrimento de la actividad física de las niñas. En respuesta a la noticia sobre los resultados de esta investigación Rosa Montero escribía en estos términos acerca de los y las adolescentes en una columna de El País:

[...] No es que no hagan deporte sino que ni siquiera caminan. Que no se menean, vaya. Que lo único que hacen es estar sentados, por lo general frente a una pantalla. [...] Yo recuerdo que, de adolescente, me daba carreras de pronto en la calle sin ningún propósito, por la pura necesidad de descargar un poco la energía que me bullía dentro (por entonces aún no existía la moda del running y tenías que correr vestida normal y simulando que se te perdía un autobús). Todos los animales jóvenes muestran esas explosiones de actividad: perritos que te destrozan la casa, terneros que brincan y cocean en los prados felices de estar vivos. Pero se ve que los cachorros humanos están mutando en setas. (Montero, 2019)

Curiosamente, ni en el artículo científico que recoge los resultados de la investigación ni tan siquiera en la noticia divulgativa que recoge la propia OMS en su página web (Organización Mundial de la Salud, 2019) se mencionan en absoluto el uso de las «pantallas» por parte de los jóvenes como causantes de la falta de ejercicio y consiguiente propensión a la obesidad, sí se hace referencia, sin embargo, a aspectos de índole social y de política educativa, aspectos culturales y económicos que inciden en el peligroso engrosamiento de estas cifras que atentan contra la salud de las futuras generaciones.

Volviendo a la cita de Sócrates, y tras la dura referencia a los cachorros humanos convertidos en «setas», ya parece ser habitual hablar denostada y gratuitamente de los jóvenes desde posiciones adultocéntricas, a las que recientemente hacíamos mención apoyándonos en las tesis de Duarte Quapper (2015) para referirnos al estudio del folklore juvenil (Abad, 2019:133). El etiquetaje social, los comentarios adultistas ${ }^{1} \mathrm{y}$ las prenociones desde las que, como adultos, se suelen analizar ciertas pautas de los jóvenes deberían ir dando paso —o mejor dicho, ser la tónica general— hacia otro tipo de abordajes que mejoren y permitan extraer el máximo partido a una adecuada comunicación intergeneracional.

El ambicioso y arriesgado propósito de este artículo no es sino indagar y profundizar un poco más en parcelas del folklore juvenil que suelen ser más inaccesibles por la condición implícita que se deriva de «hurgar» en la intimidad de los afectados, de pretender apenas abordar la comprensión de prácticas y lógicas reservadas al propio grupo de pares analizando simplemente la «punta del iceberg» de dos fenómenos diferentes y, a la vez, -interrelacionados-, en este caso por la expresión de emociones y por su interconexión directa e indirecta con Internet y las nuevas aplicaciones de mensajería instantánea como es Whatsapp. Estos dos fenómenos a los que nos referimos son:

\footnotetext{
${ }^{1}$ Entendemos por comentarios adultistas aquellos que están basados en el prejuicio y la discriminación hacia los jóvenes.
} 
a) Los juegos de grupos de pares y retos («challenges») en los que existen (o no) conductas lesivas hacia otros o hacia sí mismos².

b) Los memes y stickers ${ }^{3}$ empleados por diferentes grupos en el contexto de su comunicación cotidiana.

Para este fin, hemos llevado a cabo una investigación cualitativa que ha planteado diferentes abordajes para la recopilación de datos. Por un lado, una parte del grueso de la información ha sido recogida a través de la elaboración de entrevistas semidirigidas a adolescentes y jóvenes de ambos sexos residentes en la ciudad de Cuenca en un rango etario entre 17 y 22 años. Estas entrevistas se han realizado en el contexto asociado a alumnos de $2 .^{\circ}$ de bachillerato de un instituto de secundaria $n=6 \mathrm{y}$, por otra parte, a alumnos de $1 .^{\circ}$ y $4 .^{\circ}$ curso de grado universitario $\mathrm{n}=4$, (período 2016-2019).

Mi propia posición — supuestamente jerárquica-, debido a mi rol de profesora, era un elemento clave a atender, más aún a la hora de poder acceder a ciertos contenidos comunicativos de los diferentes grupos de jóvenes. Es por esta razón, por la que, teniendo en cuenta las debidas consideraciones éticas en relación con el consentimiento informado y la preservación de la identidad, entendíamos que tenía que articular un abordaje completamente diferente, y situarme a otro nivel frente a mis interlocutores, cuyo conocimiento y dominio del tema era muy superior al mío (al menos en lo que concierne a sus contextos y universos), para poner en práctica una etnografía, no al estilo clásico que ya cuestionó en su momento Marcus (2008) sino de carácter colaborativo en los términos que ya definió Lassiter (2005 citado en Katzer y Samprón, 2011:61) en la que nos planteamos una relación más igualitaria en donde poder consultar y consensuar con ellos/as elementos concretos y avances de la investigación. Este abordaje metodológico, ha supuesto un significativo giro a nuestra hipótesis de partida, mucho más enfocada a la idea del adolescente vulnerable y me ha permitido reconducirla a un terreno que, entiendo, ha sido articulado de modo más equilibrado y fiel a la realidad.

No obstante, parece importante señalar que somos conscientes de que este estudio debe ser considerado como estudio de caso, puesto que la muestra con la que hemos trabajado pertenece exclusivamente al ámbito universitario y de bachillerato y, por tanto, no extrapolable necesariamente a otros tipos de jóvenes ${ }^{4}$, es decir, puede contener sesgos al invisibilizar a otro tipo de grupos posibles a los que no se ha tenido acceso. Haremos mención a esta situación más adelante.

Así las cosas, he podido trabajar sobre los siguientes grupos (equivalentes a grupos de Whatsapp $)^{5}$ :

- Grupo 1: grupo de 2..$^{\circ}$ de Bachillerato de Ciencias* $n=31$

- Grupo 2: grupo de alto nivel educativo en Ciencias (local) $n=39$

- Grupo 3: grupo de alto nivel educativo en Ciencias (nacional) $n=62$

\footnotetext{
${ }^{2}$ Unas primeras reflexiones sobre los resultados de esta investigación de este fenómeno han sido presentadas el pasado mes de noviembre de 2019 en el marco del I Congreso Internacional de Innovación Docente e Investigación en Educación Superior, celebrado en Madrid, con la ponencia titulada: El sufrimiento social y su expresión en los adolescentes como grupo vulnerable. Una mirada desde la Antropología.

${ }^{3}$ Los stickers o pegatinas, son un recurso de Whatsapp con las características de un meme, que tiene una función similar al emoticono, al emoji o al gif, es decir, transmitir emociones y/o situaciones concretas. Profundizaremos en ello a lo largo del texto.

${ }^{4}$ Compartimos las teorías de Feixa (1999) donde, para hablar de juventud, tiene que hacerse desde el convencimiento de que se trata de un colectivo heterogéneo y diverso.

${ }^{5}$ Señalo con asterisco aquellos con los que he establecido una relación colaborativa.
} 
- Grupo 4: 1er año de Grado de Historia n=91*

- Grupo 5: grupo de novatos de Historia $\mathrm{n}=68$

- Grupo 6: 4. ${ }^{\circ}$ año de Grado de Humanidades $n=15^{*}$

Finalmente, se ha triangulado la información con los resultados relevantes obtenidos de la etnografía y de una exhaustiva revisión bibliográfica acerca de las diferentes categorías y temáticas centrales a esta investigación.

\subsection{El folklore en los medios digitales: un fenómeno de alta velocidad}

Tenemos esperanza con este artículo de dar argumentos lo suficientemente sólidos como para establecer una interesante conexión entre estas nuevas formas de expresión y otras anteriores, entre el «viejo folklore» y el Netlore ${ }^{6}$. Fue el folklorista Alan Dundes (1980) quien tuvo la capacidad de percibir el potencial de internet en la transmisión del folklore contemporáneo, insuflándole de nueva vida, cuando ya parecía no ser capaz de contarse nada nuevo. La concepción que había sobre ello en Europa -y en España- era bien diferente, pues el estudio del folklore contemporáneo no se estaba contemplando con la misma intensidad, debido al hecho de que sólo se categorizaba como tal folklore aquel derivado de un pasado al que había que rescatar (Díaz Viana, 2008).

Han sido múltiples los folkloristas que mantuvieron un discurso y una visión pesimista en cuanto a la progresión de la disciplina a medida que avanzaba el siglo XX, uno de ellos fue Richard M. Dorson quien auguraba que los medios masivos de comunicación eran «el enemigo del folklore» (1978: 37) y, narrativas igualmente de corte pesimista, fueron recogidas - que no manifestadas- por autores como Fox (2007) o Blank (2009).

El caso de internet es paradigmático. Cuando se pensaba que esta «modernidad» era otro de los instrumentos que iban a acabar con la creatividad del folklore, se ha visto fehacientemente que, por el contrario, se ha convertido en un transmisor e inspirador del mismo (Bronner, 2009). Para Blank, «el folklore debe considerarse como la expresión externa de la creatividad» incluyendo toda clase de canales e interacciones entre los individuos y sus comunidades (2009: 6) y esto nos lleva a pensar que ya no es exclusiva la oralidad mediante la transmisión «boca a oído», sino que se ha abierto un nuevo mundo de posibilidades que, con gran rapidez, están en constante transformación y están modificando los modos y las formas en las que nos comunicamos (Rubio-Romero y Perlado, 2015). Es un hecho constatable en los últimos años, el desarrollo de nuevos géneros, incluyendo el que en este estudio ha cobrado una especial relevancia como es el caso del meme / sticker (Wiggins y Bowers, 2015) y, no cabe duda, que habría quien pudiera confundirlo o considerarlo como una forma menor de folklore, quizá incluso como algo frívolo o trivial, pero que sin embargo permite bucear, con no poca nitidez, a través de su estudio y análisis en la realidad social y vida cotidiana de los jóvenes. Este nuevo género nos da la posibilidad de acercarnos al núcleo central del folklore: la gente (folk) que, siguiendo a Dorson, representa ese mundo diferente de lo que implica el poder (1978: 11).

\footnotetext{
${ }^{6}$ Previa y paralelamente tuvo especial relevancia el llamado «Xeroxlore» (Preston, Bell, Makin Orr 1976), el «Computerlore» (Beatty, 1976), el «jokelore» o «newslore» (Frank, 2009) que son términos que aluden al folklore de chistes, acertijos, noticias y leyendas urbanas transmitidos mediante fotocopias, mediante aquellos primeros ordenadores que no estaban accesibles a un público general o las casi compulsivas colecciones de chistes que comenzaron a volcarse en internet recogidos de la tradición oral.
} 
Y, en este caso, no se trata tanto de hacer recopilaciones de diversos materiales folklóricos y comparar sus variantes, sino que, mediante el trabajo empírico seamos capaces de intentar entender las lógicas y los contextos sociales en los que éstos fenómenos se enmarcan (Frank, 2009 y Abad González, 2019: 131).

Por otra parte, hay que tener en cuenta que el acceso no inclusivo a las nuevas tecnologías (De la Torre y Fourcade, 2012), así como otros aspectos de carácter sociocultural, trae como resultado el hecho de que se mantengan paralelamente y coexistan en la actualidad diversos canales y formas de transmisión del folklore.

\section{2. Folklore estudiantil}

Apuntaba en la introducción una cuestión que me parece relevante y claramente significativa. Son abundantes -y prácticamente mayoritarios - los estudios que se han apoyado en materiales folclóricos emanados en contextos escolares y universitarios. Si nos atenemos al caso español, esta ha sido la pauta general llevada a cabo por Gómez Cabia y Heredero (2001), Pedrosa y Moratalla (2002), Garrosa Gude (2006), Peña Díaz (2007), Díaz Viana (2008, 2010, 2017), Abad González (2008, 2019), y Gonzalo Tobajas (2013).

En el caso estadounidense es muy amplia la trayectoria en relación con la investigación de este tipo concreto de patrimonio oral y ha constituido una inspiración para el desarrollo del estudio de este tipo de folklore aquí, donde encontramos investigadores que han trabajado en Colleges y entornos de campus universitarios como Dorson (1949, 1959), Toelken (1968), Baker (1983), Fine (1999) y Bronner (2012), por citar algunos más relevantes.

Las recopilaciones más habituales nos han dejado numerosas leyendas urbanas, adivinanzas, acertijos, descripciones de ritos en fraternidades, creencias ante los exámenes, colecciones de chistes, bromas sobre profesores, juegos de beber y de besar, canciones obscenas y un largo etcétera.

Y, si hablamos de los escenarios en donde este folklore estudiantil se desarrolla, este trasciende los muros de las aulas, las residencias estudiantiles, los pisos compartidos, los espacios de ocio como cafeterías o pubs donde se reúnen, las bibliotecas, las instalaciones deportivas y todos aquellos lugares en donde tienen lugar sus actividades comunales (Baker, 1983: 107; Abad, 2019: 132) y, por si fuera poco, el nuevo escenario que comporta internet y las nuevas aplicaciones de mensajería instantánea han abierto, exponencialmente, el radio de acción para el folklorista.

Sin embargo, de todo lo anteriormente expuesto, también podemos inferir que los folkloristas se han movido para sus investigaciones - mayoritariamente - en un nicho de «confort», pues hay un porcentaje indeterminado de población joven del que desconocemos su folklore en profundidad, ya sea de aquellos grupos no escolarizados, ya de los que no acceden al bachillerato o a los estudios universitarios. Ese potencial sesgo existe, aunque, los grupos estudiados en la muestra de este estudio demuestran una variabilidad intrasocial (Mendoza, 2008) que no debemos obviar. Queda, por tanto, tarea por hacer.

\section{EXCESOS, RIESGO Y EMOCIONES AL LÍMITE: ALGUNOS JUEGOS Y «CHALLENGES》}

A las once y media de la noche del 17 de abril de 2019, cuatro «quintos» (tres chicos y una chica) que acababan de cumplir los 18 años se disponen a celebrar una fiesta previa a los mayos, junto con una veintena de amigos en el antiguo local que ocupaba 
el médico del pueblo. Los jóvenes comienzan a preparar "zurra» ${ }^{7}$ en un capacho con los siguientes ingredientes: vino, ginebra (Larios), ron Negrita, ponche Caballero, vodka blanco, Cointreau, whisky y «licor triple». También echan dos fantas y azúcar sumando un total de veinte litros.

Mientras se va preparando el «brebaje» algunos de los presentes hacen «catas» para ir probando. Al quedar todo mezclado a su gusto proponen jugar a «la abuelita». Todos los jugadores se ponen en círculo y a cada uno se le asigna un número del uno en adelante consecutivamente, y uno de ellos comienza diciendo «la abuelita tenía tres ovejitas», la persona aludida tiene que contestar «¿cómo que tres?», el que ha iniciado el juego replica «¿cuántas pues?», y el número tres contestará con un nuevo número y se repetirá la fórmula hasta que alguno de ellos se equivoque y sea obligado a beber un vaso de la «zurra». El juego continua hasta que la mayoría hayan bebido y se encuentren «chispados» ${ }^{8}$.

De este tipo de juegos para beber y juegos para fumar de los que ya mencioné alguna de sus características recientemente (Abad, 2019) hay actualmente múltiples modalidades y variantes que están en relación, no sólo con la propia diversidad geográfica o cultural de donde procedan, sino que la mayoría de los jóvenes actualmente recurren a internet para buscar nuevas fórmulas. Así pues, uno de los elementos donde radica para mí su gran interés, es el hecho de que tenemos un folklore adolescente que transita en una dirección de ida y vuelta desde lo oral a lo virtual (global) indistintamente, poniéndose una vez más de manifiesto el papel que juegan las nuevas tecnologías en los procesos de socialización de los jóvenes ${ }^{9}$, hasta el punto de que existen múltiples aplicaciones (apps) para este tipo de juegos a las que ellos recurren.

Además del juego de «la abuelita», he podido registrar en mi trabajo de campo algunos más: el llamado juego «del duro» o de «la moneda» (Abad, 2019: 140), que son pervivencias de formas clásicas que se han mantenido de generación en generación en los pueblos de la provincia, o juegos en los que se aprecia mucho más esa influencia de las fuentes externas como internet, como son el juego del «yo nunca» o el «beer pong», éste último de influencia norteamericana.

Jugar al «yo nunca» implica no sólo el consumo de alcohol sino una injerencia en la expresión de las emociones más íntimas de los miembros del grupo. Se comienza con una afirmación que puede ser — «yo nunca me he tirado un pedo en el ascensor»—, todos los del grupo que hayan hecho lo que se afirma deben beber, continuando sucesivamente con diferentes afirmaciones, que tienen en común traspasar la frontera de la esfera íntima y personal además de generar humor. En este sentido se ven dos dinámicas: cuando se trata de un grupo de amigos ya consolidado, este juego tiene una cierta caducidad en el momento en el que ya se conoce «todo» de todos, siendo nuevamente reactivado con todo su potencial de «adrenalina $»^{10}$ en el momento en que se junta un grupo con otro y se utiliza el juego como instrumento "para conocerse». En este sentido, es interesante la habilidad y creatividad de los integrantes para ir haciendo nuevas afirmaciones que

\footnotetext{
${ }^{7}$ La zurra es una bebida festiva similar a la sangría, preparada a base de vino blanco, azúcar y, a veces, frutas. En la provincia de Cuenca tiene múltiples variantes y denominaciones. Por ejemplo en Huete, es llamada «limoná».

${ }^{8}$ Recogido en Buenache de Alarcón (Cuenca). 17/4/2019.

${ }^{9}$ Lahire menciona que la adolescencia es período marcado por «socializaciones múltiples y complejas» (2007: 23).

${ }^{10} \mathrm{El}$ concepto de «adrenalina» para ellos/as es equivalente a la vivencia de emociones intensas, que varían en un abanico que va desde el humor o la risa, la vergüenza, el miedo, el enfado, etc.
} 
activen el juego, pero, lo habitual, por lo que me han referido, es que recurran a internet o a las aplicaciones del móvil que les brindan decenas de afirmaciones o preguntas comprometidas ya elaboradas, produciéndose una gamificación del folklore oral ${ }^{11}$.

Aparte de la visión «emic» que radica en el hecho de que este tipo de juegos se activan para conocerse, también debo añadir un comentario recurrente que ha llamado mi atención y es que, ellos argumentan que juegan «porque se aburren», y aparentemente, verbalizan que su umbral de aburrimiento es bajo ${ }^{12}$ y necesitan continuamente de nuevos estímulos. En este sentido, hay otros juegos a los que se recurre con cierta asiduidad como es el denominado «prueba, verdad o atrevimiento» o el popularmente conocido como «no hay huevos»» ${ }^{13}$, por el que se le exige a uno de los integrantes que haga algo ciertamente complicado, comprometido o, incluso, asqueroso. En los ejemplos que he recogido, destaco por ejemplo como prueba: «chupar los cojones de un gato (sic)» o, en otra línea $y$, no menos inquietante, hacer buscar a un miembro del grupo una conversación de cualquier contacto de su whatsapp al azar y obligarle a poner un mensaje diciendo que ha tenido un sueño erótico con esa persona para, a continuación, esperar a ver qué responde. Una suerte de ruleta rusa emocional de final absolutamente imprevisible.

Pero en este conjunto de juegos hay otros elementos que tenemos que tener en cuenta, pues últimamente ya hay estudios que alzan la voz de alarma frente a los límites de estas prácticas ${ }^{14}$. El consumo en exceso, a través del juego, de sustancias como alcohol, cannabis, marihuana u otras sustancias psicoactivas, pone en riesgo la propia salud de los intervinientes. Bestard afirma que «los grupos sociales utilizan el riesgo para controlar sus incertidumbres y afirmar sus normas en su sociedad» (1996: 16). En este marco del juego, ya sea de modo deliberado o no, se produce la embriaguez o el estado alterado de la conciencia, sobre todo si se transgreden los límites y se llega a los llamados «atracones de alcohol» (Tarragona Camacho, 2015) como mecanismo para fortalecer amistades. Así mismo, los estudios inciden en lo preocupante que resulta el hecho de que estos jóvenes perciban como carismático estar con el «puntillo» o «borracho» creyendo que esto permite o facilita avances en el terreno sexual como han apuntado Coleman y Cater (2005: 6). La tesis de Tarragona Camacho (2015) apunta a otro elemento que podría estar siendo interpretado como material folklórico (y carismático) por los jóvenes: las historias de borracheras, cuya estructura narrativa se repite en unos y otros con pocas variantes. Suelen hacer referencia a la fiesta, a la situación o contexto en donde ha sucedido, a la clase y cantidad de alcohol que se ha tomado y con quienes, adornandose el relato añadiendo todo tipo de exclamaciones como — «imenudo pedo me cogí, fuaaa...!». Suelen acabar terminando con alusiones a las secuelas de la misma (resaca, vómitos, dolor de cabeza, etc.) y al hecho de que, a pesar de todo... se lo han pasado muy bien ${ }^{15}$. Para Breton

${ }^{11}$ Tanto las aplicaciones como las webs que ofrecen estos contenidos tienen listados de preguntas para menores y mayores de 18 años. Estas últimas con un elevado componente íntimo o sexual: -«yo nunca me he acostado con un amigo/a de esta ronda»-, -«yo nunca me he masturbado en la ducha»-, -«yo nunca he hecho un trío»-, etc.

${ }^{12}$ Más aún en una ciudad como Cuenca donde los lugares de ocio son limitados, o en los pueblos de la provincia en los que, por regla general, el ocio se reduce al bar o al pub local y donde la oferta de otro tipo de ocio posible no se contempla.

${ }^{13}$ Jugado exclusivamente entre varones, perpetúa los viejos roles asociados a la masculinidad.

${ }^{14} \mathrm{Si}$ bien es cierto que hay numerosos estudios sobre el consumo de alcohol de modo general y, en concreto en adolescentes, abundar en ello excedería los límites de este artículo por lo que queremos destacar de modo específico los estudios de Coleman y Cater (2005) y Tarragona Camacho (2015).

${ }^{15}$ Estructura de una historia de borrachera extraída de una de las entrevistas realizadas (con 16 años, primera borrachera, con una mezcla de ron y vino tinto). 
(2016:108), la alcoholización tiene su origen en los antiguos ritos de virilidad, en los que resistir grandes cantidades de alcohol era sinónimo de excelencia o de virtud y no era una práctica empleada como hoy en día por su condición antidepresiva.

Maffesoli (2001) argumentaba que el juego, como modelo cultural, permite a los jóvenes rebelarse contra la sociedad del aburrimiento, una sociedad que les establece una vida programada $\mathrm{y}$, donde, como manifiesta Mendoza (2008) predomina una escolarización prolongada que impide a algunos jóvenes poder incorporarse con más prontitud a responsabilidades adultas y demora el tránsito hacia la adultez. Sutton-Smith (2008) nos habla del carácter intencionalmente ambiguo del juego, donde encontramos manifestaciones de frivolidad, reclamo de identidad grupal, ejercicio del poder, etc., y, para Huizinga, «el juego oprime y libera, el juego arrebata, electriza, hechiza» creando una tensión que es la que va a poner a prueba todas las facultades de los jugadores, tanto físicas, como intelectuales o espirituales (1954/2007: 24-25).

Por último, me interesa dedicar unas líneas a los llamados «retos virales»o challenges, todos tienen en común, como su propio nombre indica, su rápida propagación a través de redes sociales o whatsapp. Han llamado mi atención especialmente aquellos que incitan o inducen a realizar conductas lesivas para sí mismos o para terceras personas ${ }^{16}$. Voy a hacer alusión a dos en concreto: el «reto de la ballena azul» y el «reto de Momo», cuyas características coinciden en que en ambos, tras una serie de pruebas que tiene que ir haciendo la persona, incitan al suicidio como prueba final y, es un fenómeno que ha sido calificado en sí mismo de leyenda urbana al ponerse en duda que haya habido víctimas reales por haberlos llevado a la práctica.

Pero hay un elemento nuevo que distorsiona el modelo típico o al uso de la leyenda urbana, habitualmente enfocadas a la génesis del miedo $\mathrm{y}$, en mayor medida hacia un temor présago hacia «el otro» (Díaz Viana, 2004, 2017; Abad, 2008) o hacia una masculinidad amenazante (véase Abad, 2019), vemos ahora que estos retos/relatos virales, utilizando la estructura y dinámicas propias del juego de los jóvenes pretenden imponer el control mediante el miedo hacia los adolescentes con estas narrativas e imágenes explícitas de autolesiones o inducción al suicidio. La pregunta inmediata es ¿hay miedo a los jóvenes? ¿Por qué ese interés en controlarlos mediante la propagación de este material folklórico? La respuesta quizá nos la da Zygmunt Bauman «miedo es el nombre que damos a nuestra incertidumbre: a nuestra ignorancia con respecto a la amenaza y a lo que hay que hacer - a lo que puede y no puede hacerse - para detenerla en seco, o para combatirla [...]» (Bauman, 2008: 10). Un exponente más de lo que el autor denomina como «omnipresencia de los miedos» (op. cit. 13), algo a lo que los jóvenes se resisten con su Carpe Diem y que nos demuestran con sus múltiples prácticas sociales. Termino con otra cita de Bauman muy elocuente:

[...] si el temor que sembraban las fábulas morales de antaño era redentor (puesto que venía acompañado de su antídoto: una receta para conjurar la temible amenaza $y$, por tanto, para una vida sin miedos), los «cuentos morales» de hogaño tienden a ser inmisericordes: no prometen redención alguna. (op. cit. 45).

\footnotetext{
${ }^{16}$ Por internet circulan varios de estos retos, no obstante, destaco aquí las denominaciones de algunos que son extremos y ponen en serio riesgo la salud: «el reto del abecedario del diablo», «el reto de provocar asfixia/desvanecimiento», el «reto de la canela» o el «reto de comer cápsulas de detergente».
} 


\section{MeMES Y STICKERS EN LOS GRUPOS DE WHATSAPP: ¿HACIA UNA ORALIDAD COMBINADA?}

Aproximadamente, entre 2012 y 2013, una gran mayoría de jóvenes universitarios ya utilizaban el Whatsapp como el sistema de comunicación preferente frente a otras redes sociales. Para estos jóvenes no existe una frontera simbólica entre la comunicación presencial y la virtual, transitan entre ambas fórmulas sin mayor problema, les han hecho cambiar los hábitos hasta el punto de generarles dependencia. Igualmente interesante es el hecho de que, pudiendo comunicarse mediante mensajes de voz, optan preferentemente por el mensaje escrito (Rubio-Romero y Perlado, 2015). El mensaje de audio es casi equivalente a llamar por teléfono, acción que está calificada por los jóvenes de este tiempo como de «algo viejuno». Por tanto, la oralidad escrita es su opción, una opción que está demarcando con bastante claridad, a mi entender, el estatus de la persona y del grupo.

A estas alturas y, por el modo en el que se ha incardinado en la vida de todos los grupos etarios, nadie duda de la trascendencia del giro que ha supuesto para nuestra sociedad la comunicación mediada por la tecnología.

Cabe destacar que habitualmente hablamos de «conversación» por el Whatsapp equiparándolo simbólicamente a una conversación cara a cara, siendo realmente la primera una metáfora de la segunda (Baym, 1995). El intercambio espontáneo de estados de ánimo a través del envío de emoticonos, emojis, memes y stickers, facilitan la expresión y la implicación emocional (Rubio-Romero y Perlado, 2015) partiendo de niveles que oscilan desde la expresión más sencilla (el emoticono, p.ej.), a la más hiperbólica (memes y stickers), siendo una forma de expresividad muy popular y masiva como apuntábamos anteriormente.

\subsection{Acerca de los grupos de Whatsapp y sus dinámicas}

La familia cercana, las fiestas populares, la afición por un equipo de fútbol, la pandilla del instituto, el grupo de clase de la universidad, el grupillo de amigas o amigos íntimos con los que se sale de fiesta habitualmente, el grupo de un viaje de fin de curso memorable, las peñas, la «quedada» para comprar un regalo a alguien, los cumpleaños, alumnos cuyo común denominador fue un determinado profesor o profesora, un grupillo para hacer el trabajo de «geografía»y, un largo etcétera de circunstancias de las más variopintas, pueden desencadenar que se «abra» un nuevo grupo de whatsapp.

El sólo hecho de ponerle nombre al grupo ya genera una especie de activación emocional y forma parte indiscutible del nuevo juego social. «Quinta del 97», «la chupipandi», «ique arda Burgos!», «San Isidro», «Humanidades», «Graná», «amigos de siempre», «la familia», «regalo Ana», «final Champions 2018» o «novatos historia» son algunas de tantas denominaciones de grupos creados para las diferentes ocasiones mencionadas. Es importante decir que muchos de ellos, prácticamente un tercio o más, permanecen inactivos al poco de haber sido creados con algún fin concreto, es decir, ya nadie «habla» en ellos, pero nadie, absolutamente nadie, toma la determinación de «salirse del grupo». Ante mis preguntas sobre este hecho en mis diferentes entrevistas, las respuestas fueron: en algún caso, mostrar perplejidad, puesto que ni siquiera se lo habían planteado, en otros casos, argumentar que no les molesta tenerlos, que les es indiferente, pero abundando un poco, van surgiendo otras justificaciones como que no los borran para poder recordar en cualquier momento las cosas que se compartieron, que no se salen de los grupos inactivos por si acaso algún día «alguien habla» $\mathrm{y}$, por último, porque temen que si se salen del grupo «puedan perderse algo».

Nada de esto es baladí, pues forma parte como argumentaba Bauman, del miedo a la «muerte metafórica» (2008: 66): «[...] el temor a ser separado en solitario (o como 
parte de un grupo reducido) de la gozosa multitud y a ser condenado igualmente a sufrir en solitario mientras los demás prosiguen con su jolgorio y sus fiestas. El temor a una catástrofe personal [...] el temor a quedarse atrás. El temor a la exclusión» (op. cit.: 31).

Dentro de estos grupos se comparten contenidos de distinta índole, ya sea fotografías, videos, archivos o memes (Rubio-Romero y Perlado, 2015), lo que le brinda un aliciente adicional por el hecho de ser un espacio virtual participativo a la par que lúdico, pero donde opera implícitamente un tipo de control (Sánchez, 2018). La multiplicidad de grupos implica a su vez multiplicidad de identidades y una revisión consciente del tipo de contenidos y leguaje que se puede usar en unos, pero no en otros. No obstante, la tónica general que opera en ellos es el uso del humor, que, en comunidades virtuales, según Nancy Baym (1995), es un recurso que crea y refuerza la solidaridad e identidad grupales.

\subsection{El sticker: un universo más allá de la emocionalidad gráfica y fotográfica}

El biólogo Richard Dawkins concibió el meme en 1976 como una unidad cultural que buscaba la replicación continua para poder sobrevivir, en una clara similitud a los genes en el medio natural. Sin embargo, en la actualidad el meme, tal y como nosotros lo conocemos, es un contenido - normalmente jocoso - que se propaga rápidamente por internet, de persona a persona y que reflejan mentalidades sociales generales. Los memes constituyen «discursos públicos socialmente construidos» (Shifman, 2014: 8). Tal es su profusión, que ha pasado a convertirse en un todo un género de la cultura digital participativa, responde a una actividad cultural y a complejas motivaciones sociales (Wiggins y Bowers, 2015). Su estructura habitual combina una imagen visual con un texto breve, en otros casos, cuando hablamos de la categoría de «meme emergente», se hace referencia a memes que han sido elaborados directamente por los usuarios o memes que han sido modificados o remezclados constituyéndose en nuevos memes con capacidad para su replicación. Los jóvenes se convierten así en «prosumidores», es decir consumidores y productores del género a la vez (Ballesteros, 2016, Wiggins y Bowers, 2015). Cada vez que se replican y transmiten estos contenidos quiere decir que «internet se folkloriza» (Bronner, 2009).

Resulta de un gran interés desde el punto de vista antropológico, cómo este nuevo material folklórico nos devuelve una imagen muy precisa de las representaciones sociales de los jóvenes y cómo estos se enfrentan a un principio de realidad que les genera, como me han manifestado múltiples veces, una enorme inseguridad e incertidumbre (Le Breton, 2016). Los memes son considerados como «píldoras del bienestar» para paliar las tensiones diarias y la omnipresencia del humor en las conversaciones tiene mayoritariamente un carácter sanador, hedonista o placentero (Ballesteros, 2016). En palabras de uno de mis informantes: "son como el soma de un Mundo Feliz» ${ }^{17}$. Un nuevo material folklórico que, además, puede ser revisado y analizado desde la perspectiva de la teoría social de las emociones y desde la antropología de las emociones (Flores, 2010; Abad y Flores 2010).

Sólo aquellos memes que se adaptan a cada entorno sociocultural se difunden con rapidez, otros se van quedando por el camino en función de las distintas normas sociales y las diferentes percepciones según la diversidad de personas a las que llegan. Esta dinámica debe entenderse dentro de los valores de la citada cultura participativa, que emana de los internautas digitalmente alfabetizados, entre los que se encuentra la llamada Generación $\mathrm{Z}^{18} \mathrm{y}$, que tiene como valores fundamentales compartir, imitar o modificar contenidos populares, con la finalidad de reforzar la unicidad y su conectividad (Shifman, 2014: 30).

\footnotetext{
${ }^{17}$ Estudiante de $1^{\text {er }}$ curso de Historia, varón, 18 años.

${ }^{18}$ Nacidos a partir del 2001.
} 

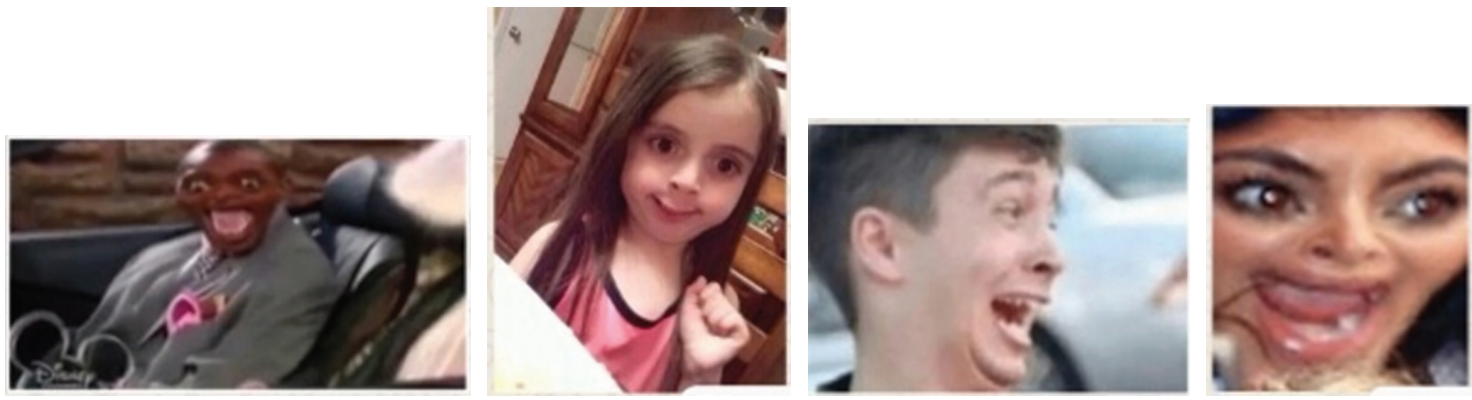

Figura 1: meme esperpéntico
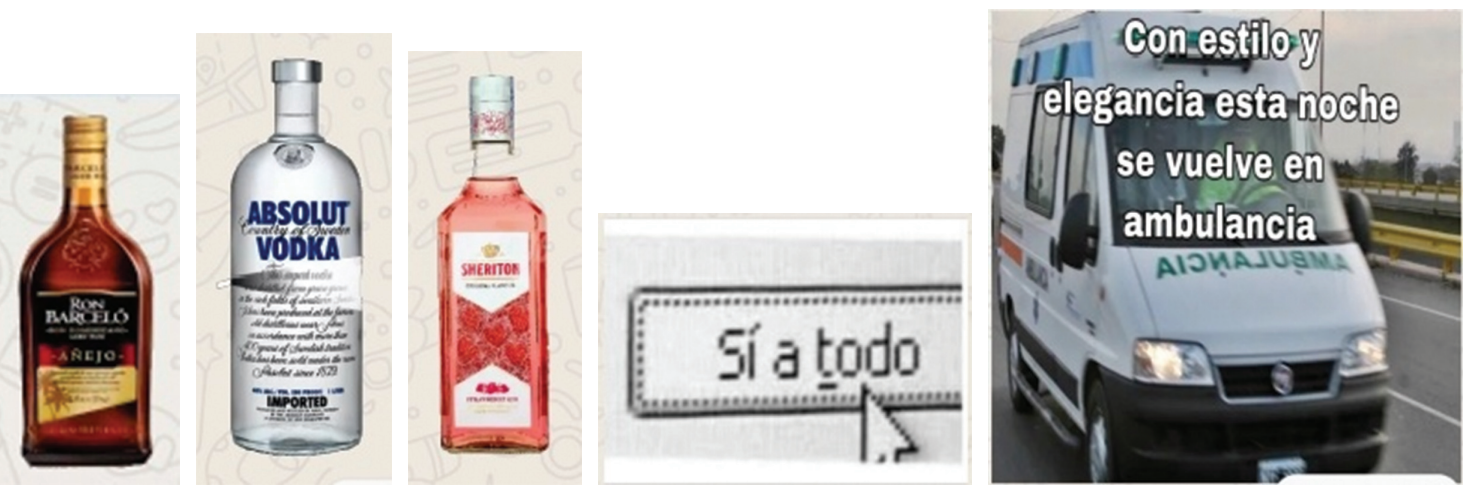

Figura 2: serie de memes alusivos al «botellón».

A lo largo de mi trabajo de campo, he podido recopilar, clasificar ${ }^{19}$ y analizar numerosos memes en su nuevo formato de sticker, dentro del contexto de las conversaciones de whatsapp de los diferentes grupos de estudiantes de la muestra. Me ha resultado imposible no establecer algunos paralelismos o asociaciones con algunos elementos que ya se encontraban en la literatura infantil y juvenil efímera (Martínez, 2018), como son algunas colecciones de cromos de chistes, en donde se incluyen ilustraciones o piezas gráficas con un breve texto, o con la lírica popular de rima fácil que tantos ejemplos nos han brindado Pedrosa (2004), Díaz Viana (2010), Garrosa Gude (2006) y Gonzlao Tobajas (2013) y, con el acertijo o el jeroglífico. Todos tiene en común el carácter lúdico, jocoso y humorístico, en donde se puede apreciar también cómo parodian su propio autoconcepto, la forma en la que se describen a sí mismos y los elementos que les dan cohesión como grupo. Algunas aleluyas, propias de la literatura de cordel, iban acompañadas de una presencia casi constante del elemento gráfico (Botrel citado en Mendoza Díaz-Maroto, 2000) y tenían series dedicadas específicamente a lo humorístico y burlesco, como las «extravagancias»o «el mundo al revés».

Una vez vistas todas las categorías de meme, podemos establecer que los jóvenes de ahora se ríen expresándose con fórmulas muy similares a las de otros tiempos. Parece haber lugares comunes, transcultural y transtemporalmente, que hacen reír al ser humano y que tienen que ver con lo escatológico, lo sexual, los insultos, las payasadas o las imitaciones (Apte 1983, citado en Jáuregui, 2008).

La caricatura, lo grotesco, lo imperfecto y la imagen esperpéntica tienen una doble función: reírse de sí mismos y reaccionar ante la violencia simbólica que impera en

\footnotetext{
${ }^{19}$ Más que una clasificación, ha sido un intento de ordenar, puesto que la singularidad de muchos de los stickers que he recopilado transitan entre varias categorías: humor, política, creencias, autoconcepto, emociones, juego, etc.
} 
la sociedad imponiendo cánones estéticos. Se utilizan para ello todo un repertorio de fotografías de expresiones faciales o situaciones disruptivas (Ballesteros, 2016).

El humor gráfico que se podía atesorar, hace no tanto tiempo, con las colecciones de cromos de chistes (Martínez, 2018:55) o que era patrimonio exclusivo de la prensa gráfica o los tebeos, ha encontrado en la comunicación memética un claro competidor, pues, en las conversaciones realizadas por este medio vemos memes seriados que se configuran de una manera similar. También es interesante señalar que el grado de aceptación de los chistes/memes se puede medir observando cuáles son aquellos que son guardados por los usuarios en «favoritos», a modo de nuevos «álbumes» virtuales.

Algunos de los que han aparecido en todos los grupos estudiados hacen referencia a «la fiesta», desde la proposición de la misma hasta sus resultados, sustituyéndose el lenguaje oral y escrito por los memes.

Los juegos de palabras, la originalidad, la habilidad, la creatividad, así como el uso de determinado lenguaje o jerga que se establecen como valores ya sea de identidad del grupo, ya como cuestión de marcar el límite etario, algo que ya veíamos en las dinámicas de los juegos de fumar y los juegos de beber (Abad, 2019), están también presentes en las conversaciones de whatsapp. He podido observar en 5 de los 6 grupos estudiados, que es habitual establecer una dinámica de «duelo» de memes a lo largo de una conversación, en donde, a propósito del tema que se esté hablando (dudas sobre exámenes, las notas que ha puesto un profesor, hechos cotidianos de la política, etc.) cualquiera de ellos comienza subiendo un meme, y acto seguido, los integrantes activos del grupo intentan igualarlo, superarlo o sorprender con el meme más excéntrico, chistoso o hiperbólico, conformándose una suerte de momento álgido de expresión de las emociones que lleva a un sentimiento equivalente a la communitas de Turner $(1980)^{20}$.
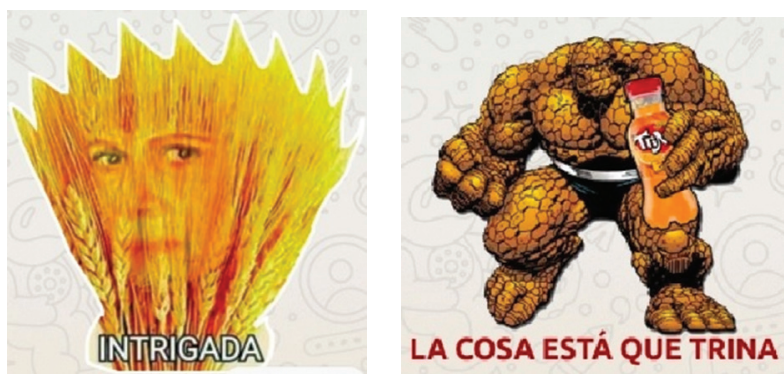

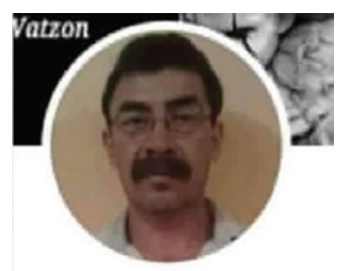

Kein Becil

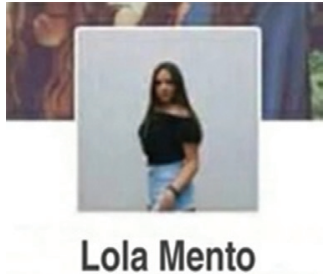

Lola Mento

Figura 3: Juegos de imagen y texto
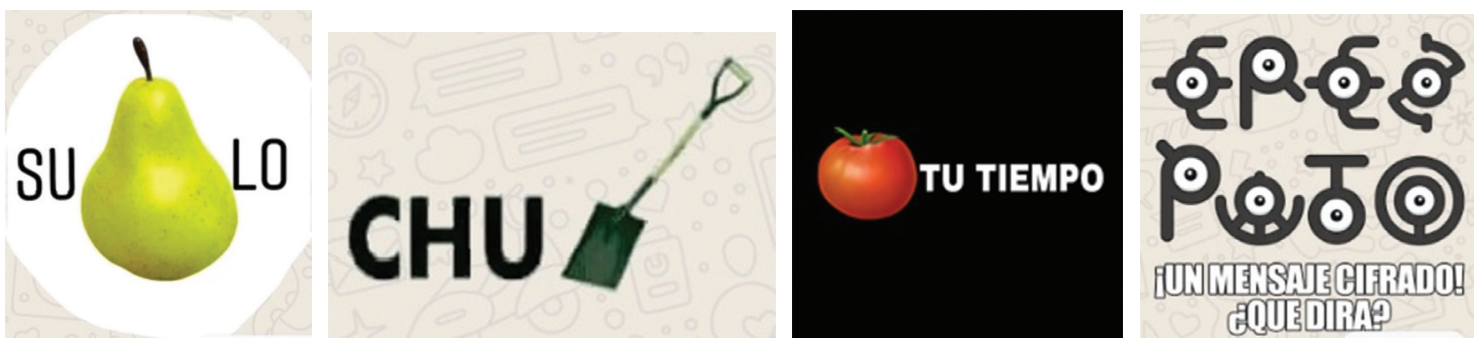

Figura 4: jeroglíficos y acertijo ${ }^{21}$

${ }^{20}$ Duelos similares a otras manifestaciones de la cultura popular reciente o actual como las «batallas de gallos» propias del rap.

${ }^{21}$ Este ejemplo recurre a la misma estrategia empleada en una vieja costumbre que muchos recordaremos: el escribir con tiza en una pizarra o en una pared «tonto el que lo lea». En este caso, «descifrar» el mensaje implica que te digan: «eres puto». Los enigmas o acertijos tienen una intención lúdica, han sido un material 

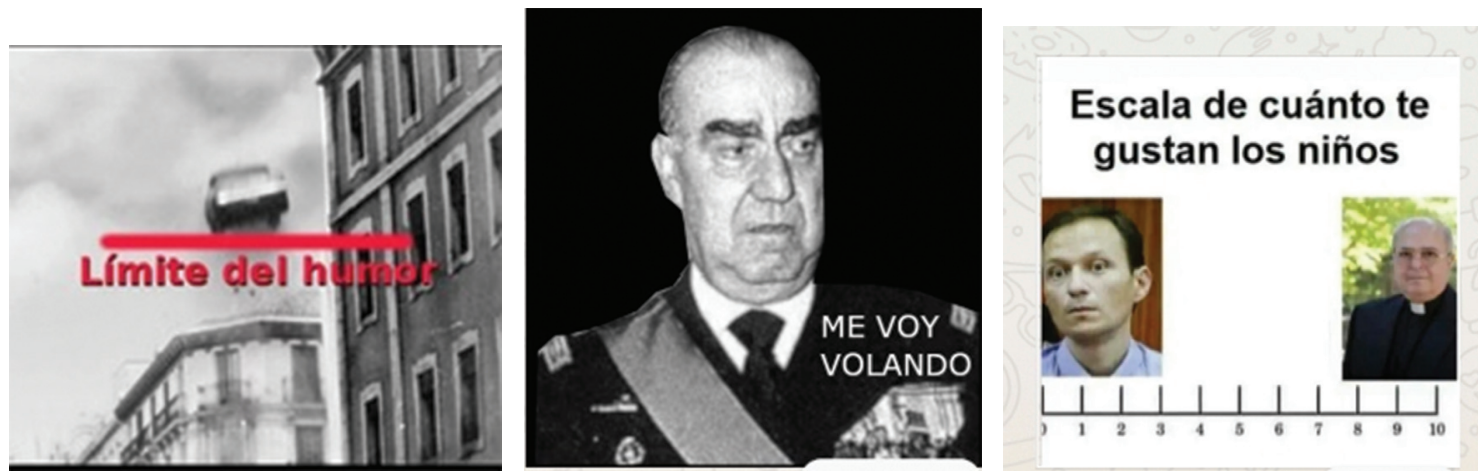

Figura 5: memes en los límites del humor

Recientemente, el departamento de arqueología del Museo de Israel, ha inaugurado una exposición bajo el título «Emoglifos: la escritura ideográfica. Desde los jeroglíficos hasta los emojis, comisariada por la egiptóloga Shirly Ben Don Evian, para poner de manifiesto que, a pesar de las grandes diferencias culturales y los miles de años que nos separan, hay muchas similitudes en el diseño y la forma entre los antiguos y nuevos modos de comunicación (Ben-Dor Evian, 2019). Las viejas y nuevas formas se dan la mano.

Para terminar este acercamiento al mundo de los memes estudiantiles, conviene recordar que la omnipresencia del humor en estas conversaciones tiene una doble vertiente, pues como argumentaba Berger (1999) el humor es capaz de mostrar los males estructurales. Botrel analiza la prensa cómica del siglo XIX donde se ríen y burlan por todo y de todo, excluyendo aquello que pueda resultar «inconveniente» o «inmoral» (2015:63). Este aspecto ha cambiado en la actualidad y genera cierta controversia, pues los límites del humor parecen estar algo difusos, llegando a ser tema de conversación en los propios grupos recogiendo el eco que tienen en la sociedad. Este tipo de humor que parece trascender los límites, está marcando la necesidad de expresar, no sólo la libertad de expresión, sino la necesidad de resolver conflictos, sentimientos contradictorios o ambigüedades. Paradójicamente, en Estados Unidos se ha creado humor sobre hechos tan graves como el 11 de septiembre, el accidente del transbordador Challenger en 1986 (Bronner, 2009), o, como es el caso del España, sobre el atentado de Carrero Blanco, que ha tenido recientemente un gran eco mediático, u otras muertes igualmente terribles y trágicas. Para Bronner, hacer chistes de este tipo de sucesos trágicos implica una demostración de dureza para no verse afectados por el horror de los hechos, aunque muchos lo calificarían de humor insensible o grosero (Bronner, 2009).

Por último, aunque hay muchas otras categorías que podrían ser incorporadas en el texto como las relacionadas con el amor / desamor, lo escatológico, lo grosero o malsonante, la burla hacia los políticos o personajes de actualidad de los que he podido constatar numerosos ejemplos, quiero terminar dedicando una atención especial a dos elementos que por su iteración en todos los grupos lo merece.

Hay una práctica bastante globalizada en los memes de lengua hispanohablante, como es el empleo explícito y consciente de faltas de ortografía. En el caso de todos los grupos de la muestra, todos pertenecientes a una comunidad educativa de nivel

recurrente y objeto de fascinación desde la época clásica funcionando «como un ejercicio de lógica informal» (Pepicello, 1987). Botrel refiere que su presencia era también común en la prensa cómica del XIX (2015: 67). 

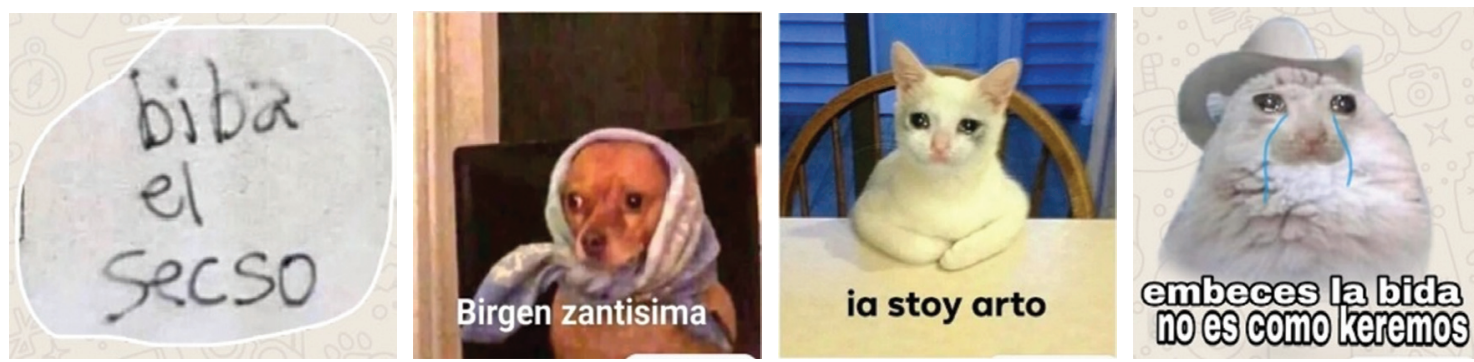

Figura 6: memes con errores ortográficos intencionados

de bachillerato y universidad, este tipo de meme es una constante y responde a una intencionalidad crítica. No he podido evitar recordar que las aleluyas en los que se podía ver el humor gráfico en relación con «el mundo al revés»: el amo tirando del carro en el que va cómodamente sentado el burro, el pez pescando al pescador o el toro toreando al torero; en nuestro caso, observamos que alumnos que han superado una enseñanza secundaria obligatoria $\mathrm{y}$, además, con alto rendimiento educativo utilizan las faltas de ortografía como recurso humorístico, de transgresión del orden y, probablemente, no exento de alguna connotación sociocéntrica y de relación de poder.

Como colofón y, siguiendo el orden de iteración de los memes mencionado anteriormente, el tipo de memes más repetidos en los grupos son los que representan la hipérbolica y satirizada ideación suicida. Son escenas con un significado ambivalente que, observadas fuera de contexto pudieran hacernos sospechar de conductas depresivas ${ }^{22}$. Sin embargo, del mismo modo que las danzas macabras medievales representaban la celebración de la vida, la expresión reiterativa de la idea de suicidio en estos grupos de jóvenes implica estados emocionales liminales y un ansia por vivir.

Durante la observación de las dinámicas comunicativas de los grupos, este tipo de memes se asociaban a alguno de los «duelos» relatados anteriormente en un contexto de límite frente a un exceso de tensión producida por la realización de trabajos o exámenes universitarios. Una forma de describir la extenuación o hartazgo máximos. Sin embargo, en las entrevistas semidirigidas, pude conocer que, tras esta aparente banalización del suicidio hay momentos en que es utilizado para expresar verdadero sufrimiento personal ${ }^{23}$.

\section{Conclusiones}

Con este estudio, hemos intentado explorar, acercar y visibilizar el universo del folklore estudiantil mediado por las nuevas tecnologías como internet o las aplicaciones de mensajería instantánea. Aún a pesar de que todos creemos conocerlo, por el simple hecho de participar de dinámicas similares — dado que no se trata de un patrimonio exclusivo de

\footnotetext{
${ }^{22}$ Las cifras, indican que en 2018 se suicidaron 268 jóvenes entre los 15 y los 29 años, mayoritariamente varones. Según Navarro-Gómez (2017), es la tercera causa de mortalidad en España dentro de este grupo de edad, debido a diversos factores, entre los que va cobrando cada vez más importancia el matonismo escolar y el ciberacoso.

${ }^{23}$ En uno de los grupos de la muestra (de 2. ${ }^{\circ}$ de Bachillerato), al menos un $10 \%$ de ellos se produjo autolesiones. La banalización de la muerte, en este caso a través de la figura de la ideación suicida, en palabras de Bauman, trasforma a la muerte en un hecho diario con la esperanza de hacerla un poco menos insoportable (2008: 60).
} 

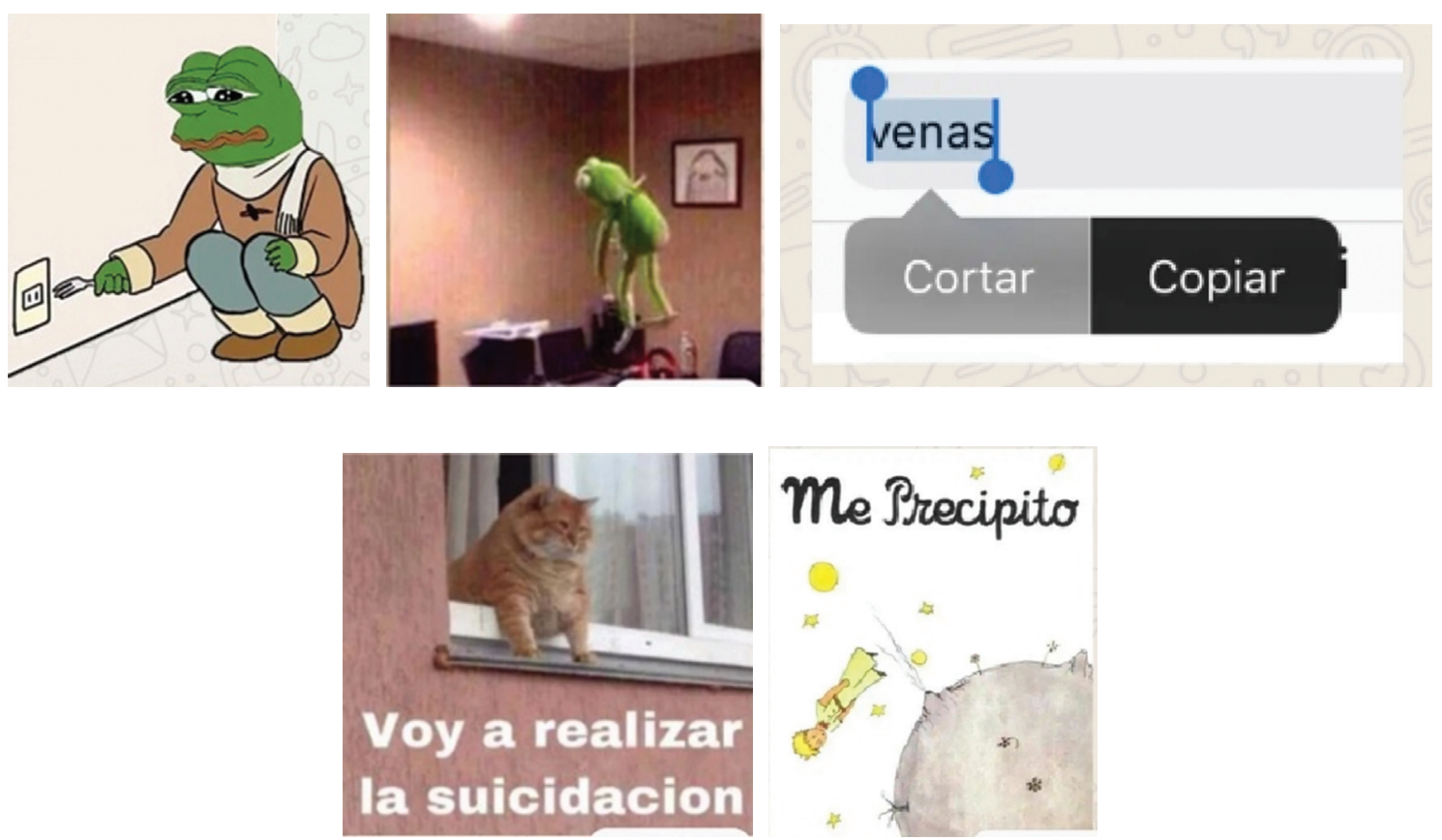

\section{Me Brecipito}

Figura 7: memes que bromean con la idea de suicidio

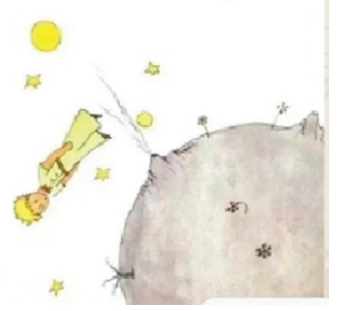

los jóvenes-, el porqué del lenguaje, los códigos y las representaciones sociales de estos jóvenes nos son desconocidos.

Sin duda alguna, alejarnos de la mirada adultocéntrica ha sido todo un reto y un ejercicio de reflexividad que ha merecido mucho la pena en aras a acercarnos a la comprensión del fenómeno.

En un trabajo empírico de estas características, resulta complicado ganarse la confianza de los grupos para acceder a ciertos contenidos de la cotidianidad. Sin embargo, aunque en un principio había cierta reticencia y pudor a permitirme conocer una de sus parcelas de intimidad, la puesta en práctica de la etnografía colaborativa, mis constantes preguntas en las entrevistas semidirigidas para intentar entender algunos elementos aislados y descontextualizados que iban surgiendo, fueron abriendo el abanico de la confianza, el interés en «dejarse conocer» y brindarme en "voz alta» sus propias reflexiones.

El folklore digital, los juegos, los memes, el humor y las emociones son indudablemente folklore $\mathrm{y}$, son los jóvenes (aunque no los únicos) con su inmensa creatividad los que le insuflan vida cada día a golpe de clic.

Hemos creído demostrar que las viejas formas del folklore inspiran a las actuales, que están de algún modo presentes y se nutren de ellas. Compartiendo, incluso los habituales prejuicios que se les otorgaban al considerarlos como frívolos, vulgares, toscos o malsonantes.

Internet impregna ya todas las facetas del ser humano, en el caso de los jóvenes, hemos podido comprobar de qué manera forma parte de sus procesos de socialización, cómo lo han incorporado en sus rituales, en sus juegos y en su vida cotidiana, interconectando ambas dimensiones y transitando entre ellas con la mayor naturalidad.

Existe un común denominador entre las formas de folklore analizadas aquí: las emociones. Bien sea porque los jóvenes buscan nuevas experiencias que brinden una ruptura de la rutinización diaria mediante experiencias hedonistas que cumplan la función 
de cohesionar a los grupos, como es el caso de los juegos de beber o fumar; bien, porque a través de las nuevas aplicaciones de mensajería instantánea, se pueden crear «grupos virtuales» que prolongan esa sensación placentera mediante la continuación del juego a través de «duelos» de memes. Estos duelos, permiten competir entre los participantes por un prestigio, al proporcionar momentos lúdicos y humorísticos donde se ponen de relieve las habilidades de algunos/as para remezclar memes o para crearlos y donde, igualmente, se consolida una solidaridad e identidad grupales.

\section{BIBLIOGRAFÍA}

Abad González, Luisa y García Saiz, Daniel (2008): «De los compraniños a la sonrisa del payaso: el papel de las leyendas urbanas en la perpetuación de miedos locales y globalizados», en Antropologías del miedo. Vampiros, sacamantecas, locos, enterrados vivos y otras pesadillas de la razón, Gerardo Fernández Juárez y José Manuel Pedrosa (eds.), Madrid, Calambur, pp.: 297- 318.

ABAD GonZÁLEZ, Luisa (2019): «Oralidad contemporánea y patrimonio cultural inmaterial: cómo registrar, catalogar y estudiar las expresiones populares de los jóvenes europeos de ahora», Revista de Estudios Europeos, 73, pp. 129-147.

BAKER, Ronald L. (1983): «The Folklore of Students», en Handbook of American Folklore, Richard Dorson (ed.), Bloomington, Indiana University Press, pp.: 106-114.

Ballestero Doncel, Esmeralda (2016): «Circulación de memes en Whatsapp: ambivalencias del humor desde la perspectiva de género», Empiria. Revista de metodología de Ciencias Sociales, 35, pp.: 21-45. DOI: empiria.35.2016.17167

Bauman, Zygmunt (2008): Miedo líquido. La sociedad contemporánea y sus temores, Paidós, Buenos Aires.

BAYM, Nancy. K. (1995): «The Performance of Humor in Computer-Mediated Communication», Journal of computer-mediated communication, 1, 2, JCMC123. DOI: https://doi.org/10.1111/j.1083-6101.1995.tb00327.x

BeAtTy, Roger Dean (1976): «Computerlore: the bit bucket», New York Folklore, 2, pp. 223-24.

Ben-Dor Evian, Shirley (2019): Emoglyphs: Picture-Writing from Hieroplyphs to the Emoji. URL: [[https://www.imj.org.il/en/exhibitions/emoglyphs]].

Berger, Peter (1999): Risa redentora. La dimensión cómica de la experiencia humana, Barcelona, Kairós.

Bestard, Joan (1996): «Prólogo», en La aceptabilidad del riesgo según las ciencias sociales, Mary Douglas (autora), Barcelona, Paidós, pp. 19-24.

Botrel, Jean-François (2015): «La risa por la risa. El ejemplo del Madrid Cómico (18831897)», IC Revista científica de información y comunicación, 12, pp.: 59-78.

Blank, Trevor J. (2009): «Introduction Toward a Conceptual Framework for the Study of Folklore and the Internet», en Folklore and the Internet. Vernacular Expression in a Digital World, Trevor Blank (ed.), Louisville (CO), University Press of Colorado, pp. 1-20. DOI: https://doi.org/10.2307/j.ctt4cgrx5.4

Bronner, Simon J. (2009): «Digitizing and Virtualizing Folklore», en Folklore and the Internet. Vernacular Expression in a Digital World, Trevor Blank (ed.), Louisville (CO), University Press of Colorado, pp. 21-66. DOI: https://doi.org/10.2307/j. ctt4cgrx 5.5 
Bronner, Simon J. (2012): «Virtual Tradition: On the Internet as a Folk System». Explaining traditions. Folk behavior in modern culture, Lexington, The University Press of Kentucky, pp.: 398-450.

Coleman, L. y Cater, Suzanne (2005): «Underage "binge” Drinking: A Qualitative Study into Motivation and Outcomes», Drugs, education, prevention and policy, 12, 2, pp.125-136.

De la Torre, Lidia y Fourcade. Helga (2012): «El uso de las redes virtuales en niños, niñas y adolescentes», Revista Infancias Imágenes, 11, 2, pp.: 69-73.

Díaz Viana, Luis (2004): «La mascota engañosa. Miedos de ida y vuelta en la era de la globalización», La ciudad es para ti. Nuevas y viejas tradiciones en ámbitos urbanos, ed. Carmen Ortiz García, Barcelona, Anthropos, pp. 299-308.

Díaz Viana, Luis (2008): Leyendas populares de España. Históricas, maravillosas y contemporáneas. De los antiguos mitos a los rumores por Internet, Madrid, La Esfera de los Libros.

DíAz VianA, Luis (2010): «Tradiciones que pasan desapercibidas: poesía popular entre los niños y jóvenes de ahora», en Tradición y modernidad de la literatura oral: homenaje a Ana Pelegrín, Pedro Cerrillo y César Sánchez (eds.), Cuenca, Universidad de Castilla-La Mancha, pp.: 113-128.

Díaz Viana, Luis (2017): Miedos de hoy. Leyendas urbanas y otras pesadillas de la sobremodernidad, Salamanca, Amarante.

Dorson, Richard M. (1949): «The Folklore of Colleges», American Mercury 68, pp.: 671-77.

Dorson, Richard M. (1959): American Folklore, Chicago, University of Chicago Press.

Dorson, Richard M. (1978). Folklore and Fakelore: Essays toward a Discipline of Folk Studies, Cambridge (MA), Harvard University Press.

DuArte QuAPPer, Claudio (2015): El adultocentrismo como paradigma y sistema de dominio. Análisis de la reproducción de imaginarios en la investigación social chilena sobre lo juvenil, tesis doctoral, Universitat Autónoma de Barcelona.

DundES, Alan (1980): Interpreting Folklore, Bloomington, Indiana University Press.

FeIXA, Carles (1999): Dejóvenes, bandas y tribus. Antropología de la juventud. Barcelona, Ariel.

Fine, Gary Alan (1999): «Methodological Problems of Collecting Folklore from Childrens», en Children's folklore. A source book, Brian Sutton-Smith, Jay Mechling, Thomas W. Johnson y Felicia R. McMahon (eds.), Logan, Utah State University Press, pp.: 121-140.

Flores Martos, Juan Antonio (2010): «Trabajo de campo etnográfico y gestión emocional: notas epistemológicas y metodológicas», Ankulegi, 14, pp. 11-23.

Flores Martos, Juan Antonio y AbAd GonZÁlez, Luisa (2010): «Abordando las emociones desde la Antropología», en Emociones y sentimientos. La construcción social del amor, Luisa Abad González y José Antonio Flores Martos (eds.), Cuenca, Universidad de Castilla La Mancha, pp. 15-28.

Fox, William S. (2007): «Computerized Creation and Diffusion of Folkloric Materials», en Folklore Forum, 37, 1, pp. 5-20.

FrANK, Russell (2009): «The Forward as Folklore: Studying E-mailed Humor», en Folklore and the Internet. Vernacular Expression in a Digital World, Louiseville, CO, University Press of Colorado, pp. 98-122. DOI: https://doi.org/10.2307/j. ctt $4 \operatorname{cgr} x 5.8$ 
Garrosa Gude, José Luis (2016): «Literatura de transmisión oral y enseñanza secundaria: cuentos y romances tradicionales en el I. E. S. La Laguna (Parla)», Culturas Populares 1 (enero-abril 2006). URL: <https://ebuah.uah. es/dspace/bitstream/handle/10017/19003/literatura_garrosa_Culturas_2006_ N1.pdf? sequence $=1$ \&isAllowed $=\mathrm{y}>$

Gómez Cabia, Fernando y Heredero, Fermín (2001): Antología de dedicatorias. Lirica popular actual de los adolescentes, Santiago de Compostela, Soláster.

Gonzalo ToBajas, Ángel (2013): Las escrituras populares escolares: estudio y antología, Alcalá de Henares, Universidad deAlcalá, UNAM. Centro de Estudios Cervantinos.

Guthold, Regina, Stevens, Gretchen A., Realey, Leanne M. y Bull, Fiona C. (2020): «Global Trends in Insufficient Physical Activity among Adolescents: A Pooled Analysis of 298 Population-based Surveys with 1.6 millions Participants», Lancet Child Adolescent Health, 4, pp. 23-35.

Huizinga, Johan. (2007): Homo ludens, Madrid, Alianza.

JÁUREGUI, Eduardo (2008): «Universalidad y variabilidad cultural de la risa y el humor», AIBR. Revista de Antropología Iberoamericana , 3, 1 (enero-abril), pp. 46-63.

KATZER, Leticia y SAMPRÓn, Agustín (2011): «El trabajo de campo como proceso. La "etnografía colaborativa" como perspectiva analítica», Revista Latinoamericana de Metodología de la Investigación Social-ReLMIS, 2, 1, pp. 59-70. URL: <http:// www.relmis.com.ar/ojs/index.php/relmis/article/view/26/21>

LAHIRE, Bernard (2007): «Infancia y adolescencia: de los tiempos de socialización sometidos a constricciones múltiples», Revista de Antropología Social, 16, pp.: 21-37.

Le Breton, David (2016): Desaparecer de sí. Una tentación contemporánea, Madrid, Siruela.

Maffesoli, Michel (2001): El instante eterno. El retorno de lo trágico en las sociedades posmodernas, Buenos Aires, Paidós.

MARCus, George (2008): «El o los fines de la etnografía: del desorden de lo experimental al desorden barroco», Revista de Antropología Social, 17, pp. 27-48.

Martínez GonzÁlez, Jesús M. a (2018): «Efímeros pluscuam(im)perfectos. Literatura infantil y juvenil (LIJ) en los cromos españoles de la primera mitad del siglo XX», en LIJ Efímera. La perfecta imperfección de los no libros, Jesús $\mathrm{M}^{\mathrm{a}}$ Martínez González y Ramón J. Freire Santa Cruz (eds.), Cuenca, Universidad de Castilla La Mancha, pp. 15-77.

Mendoza Berjano, Ramón (2008): La adolescencia como fenómeno cultural, Huelva, Universidad de Huelva.

Mendoza Díaz-Maroto, Francisco (2000): Panorama de la literatura de cordel española, Madrid, Ollero \& Ramos.

Montero, Rosa: «A la calle», El País, 8 de diciembre de 2019. URL: $<$ https://elpais.com/ elpais/2019/12/02/eps/1575305808_635521.html>.

Navarro-Gómez, Noelia (2017): «El suicidio en jóvenes en España: cifras y posibles causas. Análisis de los últimos datos disponibles», Clínica y Salud, 28, pp. 25-31.

Organización Mundial de la SAlud (2019): «Un Nuevo estudio DiRigido POR La OMS INDICA QUE LA MAYORÍA DE LOS ADOLESCENTES DEL MUNDO NO REALIZAN SUFICIENTE ACTIVIDAD FísICA, y que eso pone en peligro su salud actual y futura», 22 de noviembre de 2019. URL: <https:/www.who.int/es/news-room/detail/22-112019-new-who-led-study-says-majority-of-adolescents-worldwide-are-notsufficiently-physically-active-putting-their-current-and-future-health-at-risk> 
Pedrosa, J. Manuel y Moratalla, Sebastián (2002): La ciudad oral. Literatura tradicional urbana del sur de Madrid, Madrid, Consejería de Educación [Comunidad de Madrid], Dirección general de ordenación académica.

Pepicello, William J. (1987): «Pragmatics of Humorous Language», International Journal of the Sociology of Language, 65: pp. 27-35.

Peña DíAz, Miguel Ángel (2019): «Literatura tradicional en los textos de las agendas escolares de los adolescentes», en La voz de la memoria, nuevas aproximaciones al estudio de la Literatura Popular de Tradición infantil. César Sánchez y Aránzazu San (eds.), Cuenca, Universidad de Castilla La Mancha, pp. 111- 126.

Preston, Michael James, Bell, Louis Michael y Makin OrR, Cathy (1976): Urban Folklore from Colorado: Photocopy Cartoons, Ann Arbor (MI), Xerox University Press.

Rubio-Romero, Juana y Perlado, Marta (2015): «El fenómeno Whatsapp en el contexto de la comunicación personal: una aproximación al contexto de los jóvenes universitarios», Icono 14, vol. 13, pp. 73-94. DOI: https://doi.org/10.7195/ri14. v13i2.818

SÁnchez, Sandra (2018): «Folklore digital: la vigencia de las leyendas urbanas en los creepypastas», Heterotopias, 1(1). URL: < https://revistas.unc.edu.ar/index.php/ heterotopias/article/view/19993>.

Shifman, Limor (2014): Memes in Digital Culture, Masachusets, MIT Press.

Sutton-Smith, Brian (2008): «Play theory. A personal journey and new thoughts», American Journal of Play, 1, vol. 1, pp. 80-123.

Tarragona Camacho, Alicia (2015): «Pasar el mal trago», Etnografía del abuso de alcohol juvenil en un servicio de urgencias de Granada, tesis doctoral, Universidad de Granada.

Toelken, Barre J. (1968): «The Folklore of Academe», The Study of American Folklore. Harold Brunvand (ed.) New York, W.W. Norton Company, pp.: 317-337.

Turner, Victor (1980): La selva de los símbolos, Ramón Valdés del Toro y Alberto Cardín Garay (trads.), México, Siglo XXI.

Wiggins, Bradley E. \& G. Bret Bowers (2015): «Meme as a Genre: A Structurational Analysis of the Memescape», New Media and Society, 17, 11, pp. 1886-1906.

Fecha de recepción: 22 de enero de 2020

Fecha de aceptación: 26 de julio de 2020

$$
\text { i }
$$

